JUURNAL

of Health Inequalities

\title{
Poland's population policy during the COVID-19 pandemic
}

\author{
Janusz Szymborski \\ Government Population Council, Poland \\ Wszechnica Polska University in Warsaw, Poland
}

\begin{abstract}
The aim of this study is to initiate a discussion on the directions of research on the impact of the pandemic on demographic processes in Poland. Due to the dramatic increase in the number of deaths in 2020, the focus is on one of the four main goals of Poland's population policy, namely to improve the health of the population and reduce mortality. Some have argued that the unfavourable course of the pandemic in Poland is mainly determined by two factors: the poor health condition of the population as a result of many years of neglect of disease prevention and risk factors, and persistent weaknesses in the functioning of the healthcare system. Therefore, this paper proposes a list of research problems in the field of public health that need to be urgently addressed. Particular emphasis is placed on a syndemic approach (infections, chronic diseases, socioecological factors), as well as health education, prevention of infectious diseases, legislative measures, the social dimension of health, and interdisciplinary cooperation.
\end{abstract}

KEY WORDS: COVID-19, demography, public health, syndemic approach.

ADDRESS FOR CORRESPONDENCE: Janusz Szymborski, 42/68 Księcia Janusza Str., 01-452 Warsaw, Poland,

e-mail: janusz.szymborski@gmail.com

The World Health Organization in its resolution to the $73^{\text {rd }}$ World Health Assembly stressed that the COVID-19 pandemic highlighted the crucial role of good health as the basis of social, economic and political stability [1]. At the same time, the resolution calls on the global health community to ensure that all countries are now better equipped to detect and respond to both the COVID-19 pandemic and other serious infectious diseases, and to emerging epidemic threats [2].

The pandemic caused by SARS-CoV-2 has highlighted the topical nature of the analytical and scientific efforts undertaken in advance by the Government Population Council (GPC), including in the fields of prevention and control of infectious diseases, epidemiology and medical statistics [3]. It is now crucial to initiate a discussion on the directions of research regarding the already obvious and potential impacts of COVID-19 on individual segments of population policy. On the basis of this discussion, appropriate directional recommendations may be formulated for multisectoral, interdisciplinary research, program and implementation activities covering almost all spheres of public life. Both the current pandemic situation and effective remedial actions against future pandemic threats merit consideration. This study, apart from enumerating the problems and research questions relating to the impact of the COVID-19 pandemic on Polish population policy, comments on the actions taken in Poland to control the pandemic, as well as the premises for the debate on redefining the approach to infectious diseases in the national healthcare system.

\section{PUBLIC HEALTH RESEARCH PROBLEMS AND QUESTIONS RELATING TO THE IMPACT OF THE COVID-19 PANDEMIC ON POLAND'S POPULATION POLICY}

The course of the COVID-19 pandemic and its health and socio-economic consequences may have a detrimental effect on the already adversely developing demographic processes in Poland. Therefore, analytical and research efforts and remedial actions must be undertaken urgently. 
This will require the mobilisation of the scientific and professional communities and the creation by state authorities of conditions for appropriate ventures.

GPC defined four main population policy objectives: family policy aimed at creating conditions conducive to the implementation of reproductive plans; policy for senior citizens; migration policy; and health policy aimed at improving the health of the population and reducing mortality. Within these priorities, operational objectives and directions for the implementation of activities were adopted. This study focuses exclusively on the latter goal. It should be noted, however, that there is a close relationship between activities in the field of health and the possibility of implementing other main objectives of the population policy.

The GPC has established seven priority areas of action necessary to "improve the health of the population and reduce mortality": improvement of preventive and therapeutic care for mothers, infants and school children; reduction of morbidity and mortality due to cardiovascular diseases; reduction of morbidity and mortality due to neoplastic diseases; improving the quality of nutrition and physical activity in the society; improvement of the mental health of Polish women and Poles in different age groups; preventing and combating infections and infectious diseases; and health promotion as a key strategy to solve contemporary health problems. There is a clear need to investigate the impact of the COVID-19 pandemic on the ability to meet these priority tasks. However, in light of the influx of scientific reports from around the world on COVID-19, and the health and socio-demographic challenges specific to our country, it seems necessary to detail and supplement the activities of public health pertaining to population policy. This list is not a complete catalogue, nor is it ranked by order of importance. Valuable additions have already been made by Dr Mariola Rackaw from the Institute of Applied Social Sciences, University of Warsaw; Prof. Przemysław Śleszyński [P.Ś.], from the Institute of Geography and Spatial Organisation of the Polish Academy of Sciences; Prof. Witold Zatoński [W.Z.], from the European Observatory of Health Inequalities, Calisia University and the Health Promotion Foundation.

Detailing and supplementing the problems and research questions of public health:

- quality of communication to the public on pandemicrelated topics through official channels, healthcare professionals, mass media, social media - from the perspective of public health and health pedagogy; the phenomenon of the infodemic;

- developing reliable assessments of the effectiveness of non-pharmacological prophylactic procedures (including masks, physical distance, hand hygiene, tests, isolation, contact tracing, quarantine, assembly restrictions) as well as assessments of the health effects of violating these preventive procedures;

- transparency and fairness in access to vaccines and COVID-19 drugs, and to hospital beds;
- studies to determine whether resistance to SARS-CoV-2 is complete or partial, permanent or temporary, what is its mechanism and how best to measure it;

- analysis of the possibility of transmitting SARS-CoV-2 from mother to child in the prenatal, perinatal or postnatal period and the impact of COVID-19 infection during pregnancy on the development of the fetus and the health of the newborn;

- analysis of the risk of spreading infection to older family members and the adult community (including caregivers, teachers), by children in preschool and school age;

- the problem of the spread of the virus in multigenerational families in the context of maintaining social distance as well as the needs related to family unity and mutual help of different generations [P.Ś.];

- study of the impact of the national preventive procedures and restrictions, including the closure of facilities, on the development, physical and mental condition of children and adolescents;

- availability of pro-health services and infrastructure (sports and recreation facilities, including swimming pools and saunas), the use of which positively affects resistance to infectious diseases of the respiratory system [P.S..];

- redefinition of susceptibility to SARS-CoV-2 infection, also taking into account risk factors other than age and comorbidities; analysis of the legitimacy, especially in relation to elderly people, of the use of the concept of syndemic in connection with the phenomenon of simultaneous, pandemic, interacting, infectious disease, chronic non-infectious diseases (cardiovascular system, cancer, hypertension, obesity, respiratory system and others) and adverse socio-ecological factors;

- planning of medical care for convalescents to investigate the possible long-term health consequences of COVID-19;

- comparative analysis of the course, effectiveness of prophylaxis and treatment methods in people infected with SARS-CoV-2 and people suffering from other known viral diseases;

- dissemination of modified rules of first aid, including cardiopulmonary resuscitation and external automatic defibrillation, and the assessment of their effectiveness and safety;

- analysis of the quality of filling in death certificates of people who die from COVID-19 and the possibility of applying a similar methodology in the case of other infectious diseases;

- comprehensive analysis of the causes of excessive mortality rates in Poland, compared to most countries, due to COVID-19 [W.Z.];

- analysing the method of financing and the availability of healthcare services for health inequalities, in order to develop measures to reduce these inequalities;

- the problem of spatial dispersion and diffusion related to the recognition of the mechanisms and methods 
of the geographical spread of SARS-CoV-2 and other infectious diseases, including, for example, the impact of the so-called infectious outbreaks, transmission channels, etc., which may be of great importance in introducing rational and effective methods of limiting mobility in specific areas (territorialisation of anti-pandemic policy) [P.Ś.];

- assessment of susceptibility to infection of various social groups in terms of biological characteristics (age, gender), family and professional status, type of day mobility, etc. also in the territorial dimension, related to the features of the natural and anthropogenic environment (climatic and phenological variability, human bioclimatology, impact weather and topoclimate, e.g. air circulation, smog phenomena, etc.) [P.Ś.];

- infrastructural, urban and architectural solutions (e.g. the issue of ventilating wedges in cities and room ventilation) [P.Ś.];

- rationality and efficiency of medical, preventive and other services, including the problem of optimal spatial organisation and location of various types of medical facilities, important due to strong interregional differences between the supply of these services and the demand for them (also in connection with the expected strong changes in the demographic structure and settlement in Poland) [P.Ś.];

- pandemic monitoring: keeping comprehensive and reliable (but anonymised) databases about patients, allowing the monitoring of infections in terms of infectivity in various biological, socio-occupational, territorial groups, etc., allowing to effectively and affectively (selectively) respond to developments, also syndemically [P.S.];

- conducting multidisciplinary research and analysis of the quality of legislation in its basic functions: normative, management and judicial in the area of the healthcare system (public health, including health promotion and health education, primary, secondary and tertiary prevention; laboratory diagnostics, including microbiological; health restoration - treatment and rehabilitation, organisation; financing; medical and paramedical personnel) in order to develop the necessary adjustments and supplements, important from the point of view of effectively combating pandemic threats;

- conduct in-depth evaluation of public health education programs to prepare for the prevention and control of infections and infectious diseases; assessment of the place and role of thousands of public health graduates in controlling the COVID-19 pandemic;

- analysis of the financial resources of the National Science Centre $(\mathrm{NCN})$ and the Ministry of Health for research on various aspects of COVID-19, other infections, infectious diseases in terms of an equivalent appreciation of public health research compared to restorative medicine;

- comparative assessment of actions taken by individual countries in the scope of introducing and lifting restrictions;
- evaluation of international cooperation to combat COVID-19: bilateral, within the European Union, with the World Health Organisation;

- study of the impact of the COVID-19 pandemic, the necessary restrictions and economic slowdown on the mental condition of patients, medical staff and individual groups of the population;

- analysis of the negative impact of COVID-19 on the possibility of full implementation of all healthcare tasks (primary care, specialist outpatient care, hospital, rehabilitation), including organisational, logistic, personnel and financial problems.

Many of the above issues were included in the study by Prof. M. McKee from the London School of Hygiene and Tropical Medicine, reviewing international experiences with COVID-19 over the past year. Prof. McKee, a recognized European leader in public health [4], emphasised the huge contribution of public health in the fight against the coronavirus around the world, and drew particular attention to the fact that in the time of a pandemic it is very important to have a clear and easy-to-understand strategy ensuring that everyone has access to reliable information. On the one hand, it is the basis for the effectiveness of the public health and healthcare systems. On the other hand, reliable information is the key to gaining social trust and a necessary condition for wider involvement of the general public and individuals. In addition, honesty and transparency are needed to counteract corrupt behaviour, the manifestations of which were observed in many countries when ordering and purchasing personal protective equipment, reagents, and test kits. It seems that the process of ordering and purchasing medical equipment, drugs and vaccines also requires strict supervision. From the Polish perspective, the recommendation of Prof. McKee on the need to have national leadership in public health is especially important: "We need people to coordinate everything that is happening. We need to develop standards and procedures. We need people who can undertake modelling, who can ask the questions: If I implement this policy, what do I think will happen? And we need researchers to evaluate interventions" [5].

\section{TWO NOTES ON THE MARGIN OF THE ACTIVITIES CONDUCTED IN POLAND TO LIMIT THE TRANSMISSION OF THE SARS-COV-2, REDUCTION OF INCIDENCE AND MORTALITY DUE TO COVID-19}

It is understandable that in the current pandemic, when incidence is increasing, the medical care system is close to its capacity, and the prognosis of pandemic development is accompanied by far-reaching uncertainty, all available resources are directed to limiting the transmission of the virus, its morbidity, and providing the best possible medical care to seriously ill people in order to avoid poor prognosis and ensure recovery. Expert resources, including the GPC, can support the efforts of public 
authorities to highlight the key role of preventive medical and non-medical undertakings (e.g., wearing masks, physical distance, personal hygiene (especially of hands), quick tests, isolation and contact tracing, assembly restrictions, consistent media messaging) falling within the canon of public health, without which it will be difficult or impossible to control the current pandemic [6].

As a rule, actions taken by relevant authorities and institutions to contain an epidemic are not hastily formulated, and are initiated on the basis of expert recommendations. The time for such a debate will come after the pandemic has been brought under control, and reliable data from Poland and the world have been collected and verified in peer-reviewed scientific publications. This knowledge will be needed for solid preparation for future epidemic threats.

This part of the study focuses on phenomena that constitute an obstacle in combating the pandemic and require urgent remedial measures (infodemic), and those phenomena, which may help understand the specificity of the course of the COVID-19 pandemic, with the caveat that the search for systemic solutions requires a long time (syndemic).

\section{INFODEMIC}

Reports from many countries and our own experience show the importance of simple and practical information on: personal hygiene (washing hands, avoiding touching the nose and eyes with hands) as being of great importance to prevent the spread of infection; maintaining physical distance; eating a balanced diet rich in vitamins and trace elements; avoiding a sharp decrease in body weight; avoiding stress in everyday life, work overload and chronic fatigue; and ensuring enough sleep [7]. Prevention of certain diseases is supported by immunisation.

Unfortunately, as research shows, in Europe almost half of adult citizens lack adequate health literacy to take care of their own and others' health [8]. Low levels of health literacy are an underrated public health problem worldwide. Health literacy is understood as a set of competencies and skills in the field of broadly understood health, obtained through the proper use of information sources. Adequate health literacy allows to minimise the occurrence and impact of health risk factors on the individual and the environment in which she functions, in order to improve and maintain good health. The COVID-19 pandemic has revealed the spread of many conflicting, incomplete, or false health messages in all media - not just social media [9]. This harmful phenomenon is known as an infodemic. Therefore, the need to develop health awareness through universal health education is even more relevant than ever. Health literacy, an important task of public health and health pedagogy, should also be seen in the context of social responsibility and solidarity, and increasing its level is needed for people looking for information and health services.
During the COVID-19 pandemic, medical, scientific and health administration sources are responsible for providing the public with information that is understandable, transparent, coherent, free from hyperoptimism, devoid of stigmatisation, and maintaining standards of health pedagogy, so they can be more effectively, more confidently absorbed by the majority of people [10].

Understanding and social trust appear to be the basic conditions for overcoming the pandemic and returning to normalcy. Success will be achieved when a set of simple messages are universally accepted: a) social attitudes and behaviours (including physical distance, masks and other personal protective equipment, hygiene in everyday life, hand hygiene) are fundamental, not optional; b) epidemiological and public health interventions (testing, isolation, quarantine tracing, assembly restrictions) are fundamental, not optional; c) all currently used and potential therapies and vaccines are only a supplement to the above-mentioned actions as it does not seem possible to develop a gold standard for treating people with COVID-19 [11]. This message is based on solid epidemiological and public health data as well as clinical observations on the specifics, especially the heterogeneity of COVID-19, which does not mean doubting the achievements of modern medicine and the need to develop new therapies and vaccines. On the contrary, for example there is an urgent need to develop a strategy for future immunisation, with clear arguments on the delineation of high-risk groups, especially the elderly, medical staff, people with chronic diseases, security and transport workers, and the socially disadvantaged.

A responsible social campaign devoid of excessive optimism is needed. First-generation vaccines, prepared at an express pace, may be imperfect and may, for example, alleviate the symptoms of the disease (in some people) rather than prevent it effectively. We must be careful not to assign the vaccines an exclusive role in preventing infectious diseases, completely ignoring the at least equivalent importance beyond pharmacological methods of prophylaxis. For example, the effectiveness of vaccinations against human papillomavirus infections does not obviate the role of simultaneous education on the principles of personal hygiene and safe sexual intercourse, and does not marginalise the importance of cytological screening.

\section{SYNDEMIC}

There are many scientific reasons for treating COVID-19 as a syndrome of biological and socio-ecological interactions. A 'syndemic' is the simultaneous epidemic of chronic non-communicable diseases and infectious diseases, including the additive interactions between them and the adverse impact of social and environmental factors [12]. Adopting this concept could be important in managing COVID-19 and its health and social implications. Both at the doctor-patient relation- 
ship level, and at the health policy-citizen health relationship level, the "syndemic approach" can contribute to more effective prevention, earlier detection, more complete diagnosis, more effective treatment and rehabilitation of patients, and improved prognosis. Reports from many countries show that fighting the consequences of infection by SARS-CoV-2 will require much more attention than before, both on chronic non-communicable diseases (hypertension, obesity, diabetes, cardiovascular diseases, cancer, chronic respiratory diseases, neuro-psychiatric diseases), disability, fragility syndrome, as well as socio-economic, demographic and ecological conditions. All these threats interact, which makes people more vulnerable to each of them. This presents, in the case of COVID-19, the need to take into account preventive and therapeutic measures relating to other coexisting health problems and their determinants. The pandemic should be framed as a broader problem than just infection control and treatment of patients with severe acute respiratory syndrome. It forces an integrated approach, involving a person exposed to or suffering from COVID-19, professionals from various medical disciplines, public health and all sectors of public life, at all levels. Understanding and adopting the syndemic approach may be particularly beneficial in Polish conditions, due to the specificity of health problems and demographic features. The problem of the low status of health promotion, health education and public health in the healthcare system was raised during the debates organized by the GPC at the First and Second Demographic Congresses and at scientific conferences, as well as in the reports, positions and publications of the GPC. This affects the deficiencies in the prevention of diseases and health threats and, as a consequence, significantly higher rates of incidence of chronic diseases than in most EU countries. For example, as the research of Zatoński et al. shows, deficiencies in the prevention of alcoholism in Poland have resulted in an avalanche of alcohol deaths, especially due to alcoholic cirrhosis [13-16]. The above-mentioned circumstances may partially explain the unfavourable development of the third wave of the pandemic in Poland $[17,18]$.

\section{GROUNDS FOR DEBATE ON THE REDEFINITION OF THE APPROACH TO INFECTIOUS DISEASES IN THE NATIONAL HEALTHCARE SYSTEM}

Alarming warnings about the threats of infections and infectious diseases around the world and in Poland have been discussed for many years. Two risks - nosocomial infections and drug resistance - were identified as being of particular concern, and motivated the adoption of various countermeasures, the effectiveness of which is questionable. An obstacle to combating these phenomena may be the etiological diversity and the need for interdisciplinary, multi-sectoral cooperation. For example, dramatically increasing drug resistance is caused by the misuse and abuse of drugs by humans, as well as in animal and plant breeding, and is exacerbated by insufficient access to clean water, sanitation, along with poor hygiene conditions in healthcare facilities, farms, schools and households, improper waste management, and insufficient supervision of relevant services. In addition, drug resistance is fostered by poverty, limited access to cheap but effective disinfectants and to early diagnosis [19].

Only the emergence (and the heterogeneous course) of the COVID-19 pandemic made the whole world aware of the urgent need to rethink the previously dominant paradigms in health policy practice and to consider the need to shift healthcare systems to completely new paths or take advantage of past experiences.

\section{PUBLIC HEALTH AND HEALTH EDUCATION}

The COVID-19 pandemic affects and involves all sectors of public life and confirms the legitimacy of supplementing the biomedical paradigm in healthcare with the socio-ecological, economic, legal sphere, recognising the key role of health promotion and health education as well as disease prevention and health risks. In most countries, the biomedical paradigm prevails despite the accumulated knowledge about behavioural and socioecological determinants of health, and despite the necessity to reorient health protection in the direction of systemic, multi-sectoral actions in the field of public health as declared in international and national documents.

In the face of a pandemic, there is a growing awareness that the individual and collective responsibility of citizens, their knowledge about health, the ability to reason logically about the benefits and consequences of their own decisions on health, as well as resistance to receiving incomplete or false information, are mainly acquired and developed in kindergarten and at school. Over the past three decades, numerous attempts have been made to introduce health education to Polish schools. Theoretically, health education is very widely represented in the curricula at all educational stages, and both the scope of the content and the manner of its transmission are adapted to the perceptive abilities of children and adolescents of all ages and give the opportunity to shape practical habits during lessons related to a healthy lifestyle. In practice, there are serious doubts about the actual scale of health content and about the didactic methods used [20]. Therefore, it is important to ask the Ministry of Education and Science to conduct a thorough evaluation of the effects of this education.

One of the most important health challenges in our country is combating excessive alcohol consumption. Pikala et al. showed significant differences in deaths from alcoholic liver cirrhosis by education in the Polish adult population. Level of differences in death rates from alcoholic liver cirrhosis in some Western European countries is declining, but in Poland and neighbouring countries it is increasing. The authors describe an urgent need to 
implement national alcohol control programs in Poland which would especially target alcohol consumption in groups with lower education levels [21]. Health education and health pedagogy are lacking in all age groups.

Due to demographic changes in Poland, health education and health promotion among the elderly are gaining importance. In 2014, as part of the government program Social Activity of Elderly People, model principles, contents and methods of implementing interdisciplinary education of seniors in the field of health promotion were developed [22]. This flexible model could be used in individual regions of the country and in local communities, e.g. at Third Age Universities, Nursing Homes, Senior Clubs, Rural Housewives' Clubs, and also to expand knowledge and skills in the field of infectious disease prevention.

Health pedagogy is the theoretical basis of health education. Advocates of health pedagogy are still present in the pedagogical community, especially in the existing social pedagogy, and in the health sector. However, they are dispersed due to the disappearance of social medicine, social paediatrics, and school medicine. Today, in the time of COVID-19, they have another motivation to think and act.

\section{HEALTHCARE SYSTEM}

The COVID-19 pandemic has exposed global vulnerabilities in both public and private health systems [23]. It remains to be seen whether the healthcare systems in several countries indicated by the World Health Organisation (e.g. Japan, Vietnam, New Zealand) have coped better with the pandemic and can serve as models. However, it is advisable to conduct comparative analyses and research on an ongoing basis.

Lurie et al. note that relatively few studies deal with the situation in Central and Eastern Europe, while according to data from mid-March 2021, six of the 10 countries in the world with the highest death rates were in this region. The root cause of the unfavourable development of the pandemic in these countries may be, on the one hand, the unsatisfactory health condition of the population, and, on the other hand, systemic deficiencies in the functioning of healthcare. The pandemic has only exacerbated problems that have been observed for years. For example, health infrastructure has improved in many countries over the past three decades, but average health expenditure in Central and Eastern European countries, at $5 \%$ of gross domestic product, is still below the EU average of 9.8\% [24].

In Poland, legislative solutions in various areas of healthcare, which have been adopted in large numbers in the last three decades, are not of high quality. Legal provisions, whether concerning the entire system of organisation, the functioning and financing of healthcare, or its individual segments (e.g. mental health, healthcare for students, care for disabled and dependent people) are too often fragmented, devoid of in-depth analysis, and poor in evaluation tools for a reliable assessment of the effects. This situation translates into the low quality of health policy programs in local government units, where the wider socio-environmental context and the need for coordinated intervention in the social environment are generally ignored. Hence, in the era of COVID-19, and similar future threats to all spheres of social and economic life, it seems justified to postulate, under the aegis of the National Science Centre, to undertake multidisciplinary research and analysis of the quality of the law governing the healthcare system. This must include legislation governing all its basic functions - normative, managerial and jurisprudence - and define the healthcare system much more broadly than just medical care.

\section{THE SOCIAL DIMENSION OF HEALTH}

The COVID-19 pandemic presents another weighty argument for treating social welfare as a key component of the healthcare system. Today's problems in the functioning of healthcare systems worldwide force us to rethink the relationship between the currently dominant "biomedical paradigm" originating from Robert Koch (1843-1910) and the marginalized "social paradigm” from the works of Rudolf Virchow (1821-1902). The latter argued that "medicine is a social science, and politics is nothing else than medicine on a much larger scale. Medicine as a social science, like human science, has a duty to identify problems and try to solve them theoretically; a politician, a practical anthropologist, must find resources for a real solution ... If medicine is to fulfill its great task, it must enter into political and social life ... Doctors are the natural advocates of the poor, and social problems should be largely resolved by doctors" [(with acknowledgements to Siân Anis), J R A. "Virchow misquoted, part-quoted, and the real McCoy". Journal of Epidemiology and Community Health 2006; 60: 671]. The pandemic situation in various countries creates an opportunity to restore the importance of Virchow's work for people of all ages, especially when they are patients. These concepts in market healthcare systems cannot be entered into a spreadsheet, which is often used to assess the work and financing of organisational units and healthcare personnel.

Many problems related to epidemic threats, public health, and the functioning of health systems have been known for years in Poland, Europe and around the world. COVID-19 has only highlighted these issues, while making the necessary remedial actions urgent. Guidance for these activities may result from the work of expert teams in Poland and elsewhere.

Editors at The Lancet argue that building resilient systems to ensure the health of a population goes beyond vertical infection control programs. At the same time, they emphasise that EU Member States differ in their approach to strengthening institutions such as the European Medicines Agency, the European Centre for Dis- 
ease Prevention and Control, and pharmaceutical procurement chains and in transferring wider competences in health matters to the European Commission - "But national responsibility for health and regional and international solidarity on health are mutually beneficial and should not be treated as opposing forces" [25].

Dr. H. Szymborska from the Birmingham City Business School believes that the pandemic crisis has exposed the deep structural problems that characterise many modern capitalist economies, making many of them worse. A positive change in the face of the pandemic is the fact that the public debate has opened up to proposals that a few years ago were considered too radical. The crisis is an opportunity to rethink what we value as a society. Economic policy will not be able to bring about long-term recovery of the economy without taking simultaneous steps to counter the social and environmental crisis. The idea of rooting the economy in social life, taking into account the role of the natural environment, can help us better understand the relationships between these three pillars of our socio-economic life and take effective measures to remedy the problems facing us. In this context, Szymborska has made a comparative analysis of the economic policy strategies proposed in early 2021 by the governments of Great Britain and the USA. Overall, economic policy interventions in the UK are not addressing the structural problems as they place more emphasis on reviving supply than increasing unsatisfactory overall demand due to low levels of social welfare and progressive environmental degradation. On the other hand, the United States under President Joe Biden has turned to an economic policy that directly supports society. The American Rescue Plan, enacted in March 2021, expanded unemployment benefit programs, introduced $\$ 1,400$ direct remittances to eligible individuals, increased child tax breaks and paid sick leave for small businesses, and provided direct assistance to state authorities to address the impact of the pandemic on local communities. By prioritizing post-pandemic recovery by reducing inequalities and stimulating general demand, the American Rescue Plan emphasizes the embedding of the economy in wider social well-being. Nevertheless, despite the important achievements of the Biden plan, it is too early to say to what extent it represents a radical shift in economic thinking. Successful implementation of these proposals requires greater public investment in social infrastructure, broadly understood as an economic activity focused on providing care to society, which covers not only the social welfare sector, but also public education, healthcare, childcare and social housing [26].

Finally, it is also worth looking for these questions in the long-standing documents, positions, and summaries of debates, including those prepared by the Government Population Council. They show, among other things, a simple conclusion: if we do not focus on a broader concept of the healthcare system than at present and do not make a real attempt to build a system that treats health promotion, health education, disease and risk prevention, and social care in an equal way with medical care, then we will not be able to effectively prevent and fully control threats to the health of Poles, or create appropriate conditions to reverse unfavourable demographic trends.

\section{DISCLOSURE}

The author reports no conflict of interest.

\section{References}

1. COVID-19 response. Seventy-third World Health Assembly. WHA73.1 Agenda item 3. Available from: https://apps.who.int/ gb/ebwha/pdf_files/WHA73/A73_R1-en.pdf (accessed: 12 March 2020).

2. World Health Assembly charts course for COVID-19 response and global health priorities. Available from: https://www.who. int/news/item/05-11-2020-world-health-assembly-chartscourse-for-covid-19-response-and-global-health-priorities (accessed: 12 March 2020).

3. Szymborski J, Zatoński WA. The activities of the Government Population Council aimed at limiting health care inequalities. J Health Inequal 2017; 3(1): 30-40.

4. Shetty P. Martin McKee: champion of public health in Europe. Lancet 2013; 381(9872): 1089.

5. McKee M. The coronavirus pandemic: learning from international experience. J Health Inequal 2020; 6(2): 80-83.

6. Chu DK, Akl EA, Duda S, et al. Physical distancing, face masks, and eye protection to prevent person-to-person transmission of SARS-CoV-2 and COVID-19: a systematic review and metaanalysis. Lancet 2020; 395: 1973-1987.

7. Lerner AM, Folkers GK, Fauci AS. Preventing the spread of SARS-CoV-2 with masks and other "low-tech" interventions. JAMA 2020; 324(19): 1935-1936.

8. Sørensen K, Pelikan JM, Röthlin F, et al. Health literacy in Europe: comparative results of the European Health Literacy Survey (HLS-EU). Eur J Public Health 2015; 25(6): 1053-1058.

9. Zarocostas J. How to fight an infodemic. Lancet 2020; 395(10225): 676.

10. Brooks JT, Butler JC, Redfield RR. Universal masking to prevent SARS-CoV-2 transmission - the time is now. JAMA 2020; 324(7): 635-637.

11. MacIntyre ChR. Case isolation, contact tracing, and physical distancing are pillars of COVID-19 pandemic control, not optional choices. Lancet Infect Dis 2020; 20(10): 1105-1106.

12. Tsai AC, Mendenhall E, Trostle JA, Kawachi I. Co-occurring epidemics, syndemics, and population health. Lancet 2017; 389(10072): 978-982.

13. Zatoński WA, Janik-Koncewicz K, Zatoński M, Wojtyła A. Pogorszenie stanu Zdrowia Polaków po 2002 r. Epidemia zgonów alkoholowych [Deterioration of the health of Poles after 2002. An epidemic of alcohol-attributable deaths]. Menedżer Zdrowia 2020; 7-8: 118-123.

14. Zatoński WA, Janik-Koncewicz K, Zatoński M, Wojtyła A. Alkohol - ojciec polskich chorób [Alcohol - father of Polish diseases]. Menedżer Zdrowia 2021; 1-2: 82-87. 
15. Zatoński WA, Zatoński M, Janik-Koncewicz K, Wojtyła A. Alcohol-related deaths in Poland during a period of weakening alcohol control measures. JAMA 2021; 325(11): 1108-1109.

16. Zatoński WA, Zatoński MZ, Janik-Koncewicz K, McKee M. Alcohol-related liver cirrhosis in Poland: the reservoir effect. Lancet Gastroenterol Hepatol 2020; 5(12): 1035.

17. Informacja o zgonach w Polsce w 2020 roku [Information on deaths in Poland in 2020]. Available from: https://www.gov.pl/ web/zdrowie/raport-o-zgonach-w-polsce-w-2020-r (accessed: 12 March 2021).

18. Zatoński WA. Tajemnice pandemii COVID-19 w Polsce. Wywiad dla Pulsu Medycyny, red. Grzela E. [Secrets of the COVID-19 pandemic in Poland. Interview for Pulse Medicine, editor Grzela E]. Available from: https://pulsmedycyny. pl/tajemnice-pandemii-covid-19-w-polsce-1111988 (accessed: 27 March 2021).

19. No time to wait: Securing the future from drug-resistant infections. Report to the Secretary-General of the United Nations. Interagency Coordination Group (IACG) on Antimicrobial Resistance. Available from: https://www.who.int/antimicrobial-resistance/interagency-coordination-group/IACG_final_ report_EN.pdf?ua=1 (accessed: 3 March 2021).

20. Szymborski J. Pedagogika zdrowia - współczesne cele [Health pedagogy - contemporary goals]. Mistrzowie, Pedagodzy, Nauczyciele. Szyszkowska M (red.). Wszechnica Polska Szkoła Wyższa w Warszawie, Warszawa 2020.

21. Pikala M, Janik-Koncewicz K, Zatoński WA. Educational inequalities in mortality due to alcoholic liver disease in Poland. J Health Inequal 2020; 6(2): 134-138.

22. Szymborski J, Iwińska K, Przewoźniak K, et al. Interdyscyplinarna Szkoła Promocji Zdrowia Seniorów [Interdisciplinary School for Seniors Health Promotion]. Collegium Civitas, Klub Myśli Społecznej Inicjatywy. Warszawa 2014. Available from: https://www.civitas.edu.pl/wp-content/uploads/2015/03/interdyscyplinarna-szkola-promocji-zdrowia-seniorow-publikacja. pdf (accessed: 12 March 2021).

23. Gostin LO. The coronavirus pandemic 1 year on-what went wrong? JAMA 2021; 325(12): 1132-1133.

24. Lurie N, Keusch GT, Dzau VJ. Urgent lessons from COVID-19: why the world needs a standing, coordinated system and sustainable financing for global research and development. Lancet 2021; 397(10280): 1229-1236.

25. Editorial. COVID-19: building a stronger Europe. Lancet 2021; 397(10280): 1157.

26. Szymborska H. Polityka gospodarcza a COVID-19: radykalne zmiany czy powrót do status quo? [Economic policy and COVID-19: radical changes or return to the status quo?]. Ekonomie pandemii. Wielgosz P (red.). Biennale, Warszawa 2021 [Ahead of print]. 